\title{
Beyond the binaries: Reshaping pain communication through arts workshops
}

\author{
Abstract: \\ Pain is difficult to communicate and translate into language, yet most social research \\ on pain experience uses questionnaires and semi-structured interviews that rely on \\ words. In addition to the mind/body dualism prevalent in pain medicine (Bendelow \& \\ Williams 1995) in these studies pain communication is characterised by further value- \\ laden binaries such as real/unreal, visible/invisible, and psychological/physical. \\ Starting from the position that research methods play a role in constituting their object \\ (Law \& Urry 2004), this paper examines the potential of participatory arts workshops \\ for developing different versions of pain communication. Twenty-two participants \\ were involved in workshops using drawing, digital photography, sound and physical \\ theatre to explore pain communication. The use of arts materials made pain tangible. \\ By manipulating pain-related objects, participants could consider alternative \\ relationships to their pain. Pain's sociality was also explored, with relations with \\ clinicians and others emerging as potentially cooperative rather than adversarial. \\ Discussions considered whether pain felt internal or external, and whether it was \\ possible to conceive of a self without pain. We argue that the socio-material context \\ of participatory arts workshops enabled these alternative versions of pain. Such \\ methods are a useful addition to medical sociology's heavy reliance on qualitative \\ interviewing (Lawton 2003). (198 words)
}

Word count: 8005 words 
It is regularly acknowledged that pain is difficult to communicate and to translate into language (Kugelmann 1999; Werner \& Malterud 2003; Bourke 2014). While language's role in establishing the dimensions of pain cannot be denied (Crawford 2009), pain communication, particularly in a clinical context, remains fraught with misunderstandings (Kenny 2004; Toye et al. 2013). Pain communication is often caught in a series of binary divisions between real and unreal, clinician and patient, mind and body. Bendelow \& Williams (1995) call these 'dualisms', while Kugelmann refers to them as 'polarities' (1999) and Kenny talks of a 'process of mutual delegitimation' in clinical consultations on chronic pain. Recent sociological work (Law \& Urry 2004; Back \& Puwar 2012; Savage 2013) has emphasised the social nature of methods themselves, pointing out that they shape as well as document realities. Taking the role of methods in shaping their object of study as our starting point (Law \& Urry 2004) we examine how participatory arts workshops might constitute pain communication differently. Following Radley's (2010) conceptualisation of methods as creating 'versions' of experience, we suggest that the issue is not one of finding an accurate representation of pain but of creating new 'versions' that communicate aspects of the pain experience.

For Bendelow and Williams, the dominance of the medical and psychological models of pain has led to a neglect of the individual experience and subjectivity, 'which in tum leads to a limited approach towards sufferers and a neglect of broader cultural and sociological components of pain' (1995:146). Our workshops brought together people with pain, carers and clinicians, to explore pain communication collectively, outside of clinical relations and institutions. We argue that the use of arts materials 
changed social relationships and enabled forms of pain communication that often bypassed or problematized the binary terms that have characterised both lay and scholarly discussions about pain communication. This in turn produced a broader account of pain and the social relations surrounding it.

\section{Pain binaries and research methods}

Research on the meaning of pain for those who experience it has frequently used questionnaires or interviews, each of which produces certain versions of pain (Smith 2008; Miczo 2003). In clinical settings and research, the intensity of pain is often measured using numerical rating scales (from $0-10$ or $0-100$ ). Patient interpretations of these are often complex and idiosyncratic, weighing concerns such as function and mobility rather than objectively assessing an internal state (Williams et al 2000).

Questionnaires may limit the communicable versions of pain to those already set out by the questionnaire's format, enabling the patient to communicate their pain in a way that is actionable for the clinician, but not necessarily in a way that is satisfactory for the person with pain (Smith 2008).

Qualitative systematic reviews and metaethnographies of qualitative pain research have found that key themes include discomfort, loss and worry for the future; disempowerment, leading to hopelessness; intrusion on the self; family strain, loss of employment, social withdrawal; unsatisfying relationships with healthcare, and less frequently, learning to live with pain by coming to terms with it (Macneela et al 2013), as well as 'pain as an adversarial struggle' (Toye et al 2013). Broadly, interview studies have found that a major part of this struggle concerns the legitimacy 
of reported pain, with people feeling disbelieved or misunderstood by clinicians, friends and family (Toye et al. 2013; Werner \& Malterud 2003; Kenny 2004). This is related in part to its invisibility (Kugelmann 1999; Rhodes et al. 1999). Linked to this is the question of pain's purported origin in the mind or the body (Bendelow \& Williams 1995). For people with persistent pain, this issue bears on the legitimacy of their complaints of pain, in a context where clinicians are often unable to find mechanical causes. Kenny (2004)'s interviews with pain patients and clinicians discovered that communication failed because doctors felt the need to convince patients of the psychogenic nature of their pain, while patients remained convinced that their pain was biogenic in nature. In such communication, an expert/patient binary emerges, with the legitimating power distributed to favour the expert.

Interview studies highlight the defining concern of people with pain to assert the reality of their pain. The real/unreal binary is bolstered by a series of other binaries which marginalise their experience, including visible/invisible, mind/body, and expert/patient. Such binaries also afflict scholarly theorising about pain, limiting the versions of pain articulated in academic and clinical literatures (Morris 1991; Thacker 2015; Quintner et al. 2008).

While interview studies offer important insights into the experience of pain in patients' own terms, they are also limiting. Medical sociologists have been noted to have 'an overwhelming fondness for the research interview' (Lawton 2003: 35). Richardson's introduction to Sociology of Health and Illness's virtual special issue on pain observes that the need to go beyond the interview 'is equally applicable to pain, particularly given the documented difficulties with articulating pain experience' 
(2009). Narratives produced in interviews do not stand alone as 'the authentic voice of the patient underdog as opposed to the voice of dominant medicine' (Bury 2001: 281). Interviewees are also likely to have previously reflected upon the topic of an interview by virtue of being asked to participate. As Miczo (2003) argues, "if we ask patients about illness, then we will get narratives about illness. However, given the opportunity, would patients prefer to downplay, or even ignore, the role of illness (a stigmatised condition) in their lives?" (2003: 485).

Pain researchers have also experimented with forms of data beyond the interview. Broom et al. (2015) suggest that diary methods allow more time for reflection and reduce the self-presentational elements of face-to-face methods. The role of gesture in communicating pain has also received attention (Hydén \& Peolsson 2002).

Rowbotham et al's video study of descriptions of people's most recent pain experience identified gesture as a key source of information, usually in combination with speech, about the location, size, quality, intensity, duration, cause, effects, and awareness of pain (2012: 7).

Conversation analytic studies of pain communication have emphasized the interactional nature of pain (Heath 1989; 2002; Clemente 2009; Jenkins 2015; Jenkins and Hepburn 2015) both in everyday contexts and in clinical consultations. Patients find opportunities to enact their pain in consultations with general practitioners:

'they infiltrate their utterances with breath tokens and quavers, coupled with various visual displays such as tightening the jaw. In this way the patient reveals the pain of his complaint while cooperating with the diagnostic enquiries... there is evidence to suggest that no direct correspondence may 
exist between the "stimulus" and the expression of suffering (1989:123).

Jenkins and Hepburn document the 'language games' associated with pain expression, highlighting how children's pain is negotiated conversationally with parents in terms of its severity and authenticity (2015: 487). Jenkins (2015) argues that 'the authenticity and nature of a child's experience is produced, amended, resisted or accepted in the [conversational] turns that follow, with varying degrees of success' (2015: 308). Children are active agents in these interactions, who not only assert and describe their sensations of pain but also contest and rework their parents' descriptions and attributions.

These studies have the advantage of using the language of people with pain, elicited outside the setting of a formal interview. While their analyses do not point to 'binaries' as such, these interactional studies also highlight the importance of proving, demonstrating, and verifying pain. The reality, or not, of pain is what is at stake. Verification of pain is performed through conversation: pain is taken up, accepted, or downplayed or rejected by the conversational partner.

Conversation Analytic work on pain has productively used video recordings of pain in naturally-occurring contexts, overcoming some of the problems of the contrived nature of interviews. Nonetheless, as Billig (1999) has argued, Conversation Analysis is not a neutral practice in itself, but co-constitutes particular realities, giving theoretical and methodological primacy to the micro-details through which communication is achieved. Acknowledging that all research methods co-constitute their objects (Law \& Urry 2004), our research asks: could more social, relational versions of pain be constituted through alternative, arts-based approaches? 


\section{Potential of arts-based methods}

The relationship between art and pain is widely recognised. Morris (1991)'s study of the 'cultures of pain' highlights the complex relations around how pain is used creatively among artists, dancers, and authors. Scarry (1985) identifies the work of art as one way of transforming pain, part of 'making' what pain 'unmakes'. She suggests that through this, 'pain is moderated into sustained discomfort; and the objects of imagining, though individually moderated into fragmentary artifacts, are collectively translated into the structures of civilization' (1985:172). Yet it is worth noting that the relationship between pain and creativity should not be taken for granted; empirical studies have noted a fraught relationship in which pain can as easily hinder creative output as promote it (Vick \& Sexton-Radek 2005)

Visual methods have a wide range of uses in medical sociology (Harrison 2002). Art images can be a catalyst for discussing the meanings of pain (Bendelow 2000). For Radley \& Bell (2007), in relation to breast cancer activism, art is a way of transforming individual illness experiences into collective identity (367). They highlight the need to focus on "how such artworks "work" in relation to sufferers who view them, or indeed about their context of production (2007: 383). Recognition of the issue in one another is a key part of sustaining communities of activism, and artwork, they argue, plays an important role in this.

Arts-based methods are becoming more widespread in health research, and reviews have found that they are good at helping people to 'express experiences that are too difficult to put into words' (Stuckey \& Nobel 2010: 256) and producing and 
disseminating new forms of knowledge about health-related issues (Fraser \& al Sayah 2011). Deborah Padfield's (2003; 2011) collaborative work with pain patients is notable in producing impactful expressions of pain. Both patients and clinicians reported improved communication following the use of pain images in their consultation (Padfield et al 2010). Analysis of drawings by people with pain has found themes such as pain as an attacker, being trapped by pain and the future with pain (Phillips et al, 2015) as well as loss of self, a redefinition of self, feeling isolated in relations with others, and being hopeful (Henare et al 2003). These latter themes echo the topics highlighted in interview studies, with a greater emphasis on the future and the potential for hope. Having 'others' acknowledge the public declaration of self' that emerges in a group activity can be productive (Henare et al 2003: 516); suggesting that arts workshops may offer transformative potential beyond that of drawing alone.

This paper emerges from a 17-month study of the potential of visual and arts-based methods to communicate pain. The primary research question explored by the workshops was, how can interdisciplinary methods from the arts, humanities and social sciences be used to communicate the multisensory and nonverbal aspects of pain experience? Our research aimed to investigate whether arts methods might communicate multisensory and nonverbal dimensions of pain to augment language, examining how the versions of pain produced in arts workshops differed from those produced through other methodological approaches.

\section{Methods}


The workshops

We held four full day workshops on Saturdays over the course of two months (February-March 2014). We selected four contrasting artistic methods, scheduled to move from more traditional media (images, photography), to media less frequently used in social research (sound, physical theatre). Each workshop had two leaders recruited for their experience in the relevant artistic medium. Workshops were a mixture of brief presentations by workshop leaders, and individual, pair, or group exercises, interspersed with regular, catered breaks. Each workshop incorporated at group discussions to debrief the exercises, discuss the meaning of the outputs, and provide feedback.

The first workshop, 'Imaging and Imagining Chronic Pain', was co-led by a neuroimaging specialist and a visual artist. It included a presentation on the ambiguities of fMRI scanning in relation to pain, a visual brainstorming exercise and a body scan meditation led by the artist. Participants produced mind maps of pain descriptors (comprising words and images) and individual drawings, paintings and sculptures.

The second workshop, 'Body Mapping', was co-led by a photographer and a bodywork practitioner. The bodyworker introduced his method and its relevance to pain. The photographer supported participants to work in pairs to create a digital photograph of objects they had brought to represent their pain. After experiencing or attempting some bodywork, participants made a second image transforming the original in some way. 
The third workshop, 'Soundscape of a Body in Pain', was co-led by a sound artist and a music therapist. They introduced the idea of a 'sonic clinic', where each person brought a sound that represented their pain for 'treatment' through modification of some sort. Participants explored a variety of sounds as pain descriptors and then created and recorded group improvisations.

In the final workshop, 'Spatial Mapping', a physical theatre practitioner and a cultural geographer led a series of exercises exploring bodies and space. In silence, participants made drawings and collectively re-arranged their images of spaces associated with pain to form 'maps'. Later, they 'sculpted' an imagined character onto the body of another and put their human sculptures into a scene together, exploring issues of social exclusion and isolation.

Three researchers facilitated by leading introductions and concluding discussions and organising practicalities such as materials, catering, and recording. Otherwise the practitioner co-leaders took charge of the activities, and we participated in workshop activities. In doing so we aimed to create a non-hierarchical and participatory dynamic which did not replicate the clinical setting in which some people offer narratives, to be observed and recorded by other people (Tarr et al 2017). Two researchers drew on first-hand experience of chronic pain and chronic illness; one drew on everyday experiences of pain. We framed the workshops as an opportunity for all participants: people with pain, carers, clinicians, researchers and workshop leaders alike, to collectively explore arts practices and meanings of pain. The outcomes of the workshop were therefore co-produced by workshop leaders, 
participants, and the research team. We do not claim that the versions of pain produced in the workshops were 'representative' or 'natural' in any way. Rather, the workshops were intended as explorations of alternative versions of pain (Tarr et al 2017)

\section{Participants}

People with pain and their carers were recruited through social media and printed leaflets in local cafes and health centres. Clinicians were recruited through existing contacts and members of the project advisory board. This community-based method of recruitment may have helped insulate the workshops from hierarchical clinical relations. It may also have produced a group of relatively empowered participants who are managing to live with their pain, compared to studies based on clinical participants, who self-evidently 'have not learned to live with chronic pain' (Risdon et al. 2003: 376).

Participants were invited to take part in as many workshops or as few as suited them. In total, 22 people took part, five of whom participated in more than one workshop, and two of whom attended all four. Of these, 14 were people with pain, six were clinicians (mainly physiotherapists), and two were carers. Pain and chronic illness interfered significantly with workshop attendance, and between four and six participants per workshop (including many continuing participants) signed up only to cancel at the last minute due to poor health.

\section{Table 1: Attendees at the four workshops}




\begin{tabular}{|l|l|l|l|l|}
\hline Workshop & Imaging and & Body Mapping & Soundscape & Spatial \\
title: & Imagining & & Mapping \\
\hline Registered & 12 & 18 & 10 & 11 \\
\hline Attendees & 4 & 11 & 5 & 5 \\
\hline Clinicians & 4 & & 1 & 1 \\
\hline Carers & 0 & 1 & 1 & 1 \\
\hline Total & $\mathbf{8}$ & 1 & $\mathbf{6}$ & $\mathbf{7}$ \\
Attendees & & $\mathbf{1 3}$ & & \\
\hline
\end{tabular}

Participants self-identified as having pain or being carers or clinicians, and defined pain in their own terms in order to avoid divisions between those with official diagnoses and those without. During the workshops, people mentioned suffering from a range of conditions including autoimmune disorders such as rheumatoid arthritis and kidney conditions, Crohn's disease, brain injury, spinal injury, trigeminal neuralgia and chronic low back pain.

\section{Ethics}

The project received ethical approval from the LSE's Research Ethics Committee. All participants were sent an information sheet and consent form when they registered which was discussed and signed prior to each workshop. Arts-based outputs were licensed under Creative Commons, enabling the research team and participants to reuse them freely. Participants' comfort was a key ethical concern. The workshops took place at a healthcare centre used primarily by occupational therapists and physiotherapists; it therefore had a range of equipment including pillows, orthopaedic 
chairs, physio balls, mats and beds to assist in making participants comfortable. Transport expenses were reimbursed, including taxi fares for those unable to take public transport. The atmosphere of the workshops was flexible and respectful of participants' needs for breaks.

\section{Data collection}

Each workshop produced approximately five hours of video recordings, two sets of fieldnotes written by the researchers, anonymous evaluation forms completed by participants and arts outputs including drawings and sculpture; digital photographs; sound recordings; drawings and spatial arrangements of images; and physical theatre tableaux. Group discussions were transcribed from the video footage, and included written descriptions of movement, activity and interaction. As we have outlined elsewhere (Tarr et al, 2017), each of these provided partial insights, but none of the data could be understood in isolation. The circumstances of the workshops and small group work meant that not all interaction could be recorded. Moreover, silent processes such as the creation of artworks could be analysed for their meaning but did alone provide insights into the processes of translation from pain to art that occurred. The video was not suited to micro-level analysis (Heath, Hindmarsh and Luff 2010), but was largely a mnemonic tool and prompt rather than the primary focus of our analysis.

\section{Data analysis}

We used thematic analysis to identify the 'versions' of pain produced in both the textual and the non-textual data. Thematic analysis is a method for analysing meanings (Braun \& Clarke 2006) and summarising them in terms of 'themes', i.e. 
interpretive labels given to recurring patterns of meaning in the data (Attride-Stirling 2001). Thematic analysis is a 'bottom-up', meso-level form of analysis focusing on the content of communication rather than micro-level conversational acts and interactions. It does not prescribe particular theoretical commitments (Braun \& Clarke 2006) and is applicable to non-textual data as well (Gleeson 2011). As we have indicated, this study assumes that meanings or versions of pain are produced in transient communication, and vary according to the media and social relations of their production.

The analysis followed the general steps of thematic analysis outlined by Braun and Clarke (2006: 81). In the first phase of analysis, one member of the research team coded the textual and non-textual materials to produce an inductive thematic coding frame. The unit of analysis was an utterance, sequence, object or representation in which a distinct meaning of pain was conveyed. The research team then discussed the coding frame in relation to the literature. The second, interpretative stage was done by a second team member, with the earlier inductive themes of 'qualities of pain'; 'consequences of pain'; 'relationships and pain' rearranged into organising themes and sub-themes, and then refined in relation to existing literature from the qualitative studies of pain discussed above. Key organising themes were coded at this stage as ‘descriptions of pain' (including its qualities); 'relations around pain'; and 'where pain is' (its location inside/outside the self). The three sections below on 'making pain material', 'the sociality of pain' and 'pain, self and space' build upon these themes analytically to interpret how the material, social and spatial conditions of the workshops yielded alternative versions of pain to those usually described in qualitative, interview-based literature. 


\section{Findings}

\section{Making Pain Material}

Working with arts-based methods allowed the possibility of making pain tangible, giving it a material basis outside the individual. Objects, sounds and photographs elicited participants' relation to pain. Externalising pain in this way enabled participants to relate to pain 'objects' with some distance, and to consider how these relationships might be moulded, modified or transformed.

For those participants who attended more than one workshop, these shifts were sometimes reflected in their discussions. One participant with an interest in visual art found it hard to wrap her mind around how the third workshop topic, sound, might relate to pain, 'beyond cries'. She couldn't imagine how it would work, but became 'a total convert' (Jen fieldnotes).

Versions of pain

The analysis of the arts outputs identified the 'versions' of pain produced in the workshops. The physical objects, sounds and photographs chosen to represent pain were multifaceted, expressing three main themes. The unpredictability of pain, and the associated anxiety of constantly anticipating an attack of pain was conveyed by metaphors including the shortcircuiting of bare electrical wires, the sound of intermittent volcanic explosions, and the anticipation of the neighbours' dog's bark. 
Its impenetrability and incommunicability were conveyed by objects including a stone, or an empty box (Figure 1).

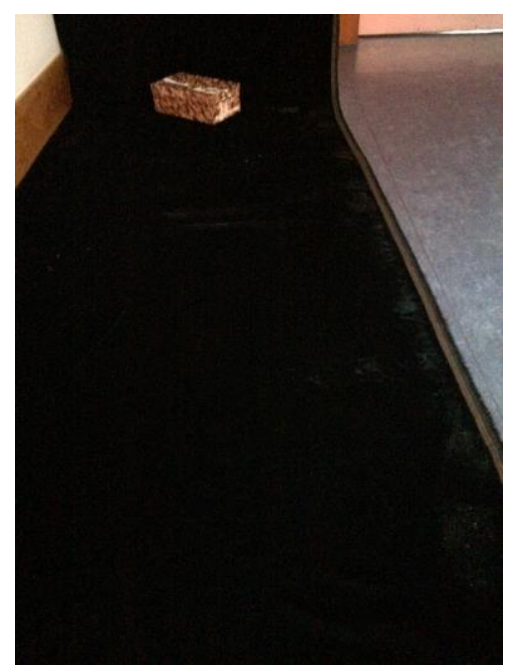

Figure 1: Pain's impenetrability: Jude's ‘before’ image (CC-BY-ND-NC)

The imagery and sounds used to convey the qualities of pain were powerfully evocative (e.g., sheets of metal grinding against one another; rats gnawing at one's bones; a shrieking tuneless violin string; the active intentional wrapping of a red, immobilising thread around a tender plant's stem). These images had a visceral impact that was far more intense than linguistic descriptors of pain (such as 'burning', 'stabbing'), and thus conveyed the extraordinariness of persistent pain.

But the third theme was the everydayness of pain (e.g., a computer mouse; a gimble to support books and thereby ease neck strain; a set of interlinked safety pins; a fridge door; cafes; coffee; a shopping centre; bus seats). Some of these items were chosen to show how apparently innocuous objects or activities can present almost insurmountable challenges. In the 'spatial mapping' workshop, a cheerfully decorated coffee shop was furnished with impossibly hard, uncomfortable chairs. An ordinary 
kitchen fridge door expressed the feeling of dread associated with opening the fridge to take out the injections one participant needed to manage her condition. For others, everyday spaces such as a cafe or a theatre expressed sociability and possibility. In one interaction in the Space workshop, participants gave competing interpretations of a group of images of crowded public places:

Sarah: For me those are all spaces of just, exhaustion, I just feel stuck, the crowd, and I've been in those spaces where you just can't get out and you're tired and you want to go home and there's no way, because there's so many people. They're all London spaces for me [laughter].

Gemma: For me it's actually quite positive in the sense that you're out and about, you're not just sitting at home, worrying about pain, and being born and bred in London for me, I would feel very sad and lonely if I was put somewhere in the countryside just looking at other villages. So for me, that's life, and I do go to the theatre when I'm well. I try to avoid situations like that shopping centre [laughter] unless you go early in the morning, you'll end up with thousands of people. So for me that's normality, and if I get really tired I can go home early. I'd rather be around people, I'd rather be with people. [...]

Ellie: I have the opposite relation to that because my experience of pain is that it's always when I'm in a public space and there's nobody that-because I need to lie down as soon as I feel it otherwise I just faint, and so I don't, those spaces are really frightening to me, but I'm lucky because my pain comes down, I 
know when it's going to happen, so I don't, I can go to those places when I know I'm fine and then when I have the pain, that's the most terrifying.

Similarly, an image of a horse in a swimming pool was interpreted positively by some people, as the horse being supported by the water, undergoing hydrotherapy for an injury, while others saw it as a struggle, an image 'about exhaustion and working through that at that point, at that edge. Still keeping going' (Luis). Coffee, signifying sociality to some, brought on symptoms for others. The arts-focused nature of the workshops supported an ethos that there was no one 'right' interpretation of an object, and that individual interpretations were all valid. In evaluation forms, participants articulated their appreciation that the workshops felt non-judgemental and inclusive.

\section{Transformations of pain}

Representing pain through objects also opened the possibility of changing one's relationship to that object. In the second workshop, participants were asked to take a digital photo of their object in one context, then later to imagine it being transformed in some way. The 'after' images did not make the pain objects go away. The acontextual black background shown in some of the first images, such as the one above, does not appear in the transformed images. More whole bodies and faces, rather than body parts, are shown. Hands hold objects together (a 'ball' of pain; a computer mouse; a participant receiving bodywork); objects are let go (the impenetrable stone; the tender plant unwrapped and untied from the participant's wrist and the materials laid out separately); unwrapped or untied (the plant; a series of photos of the unravelling of a taut ball of elastic bands); or conversely wrapped up (a 
tennis ball nested in string; electrical wires grounded by attaching rubber balloons to each end, figure 2). Some shifts from the first image to the second are subtle, such as a blue sky instead of a grey one behind a reading gimble, suggesting a shift in thinking or attitude rather than circumstance. Others are more dramatic (unwrapping/untying). Overall, these images add context, whether through another person or a wider-angle shot or a different background.

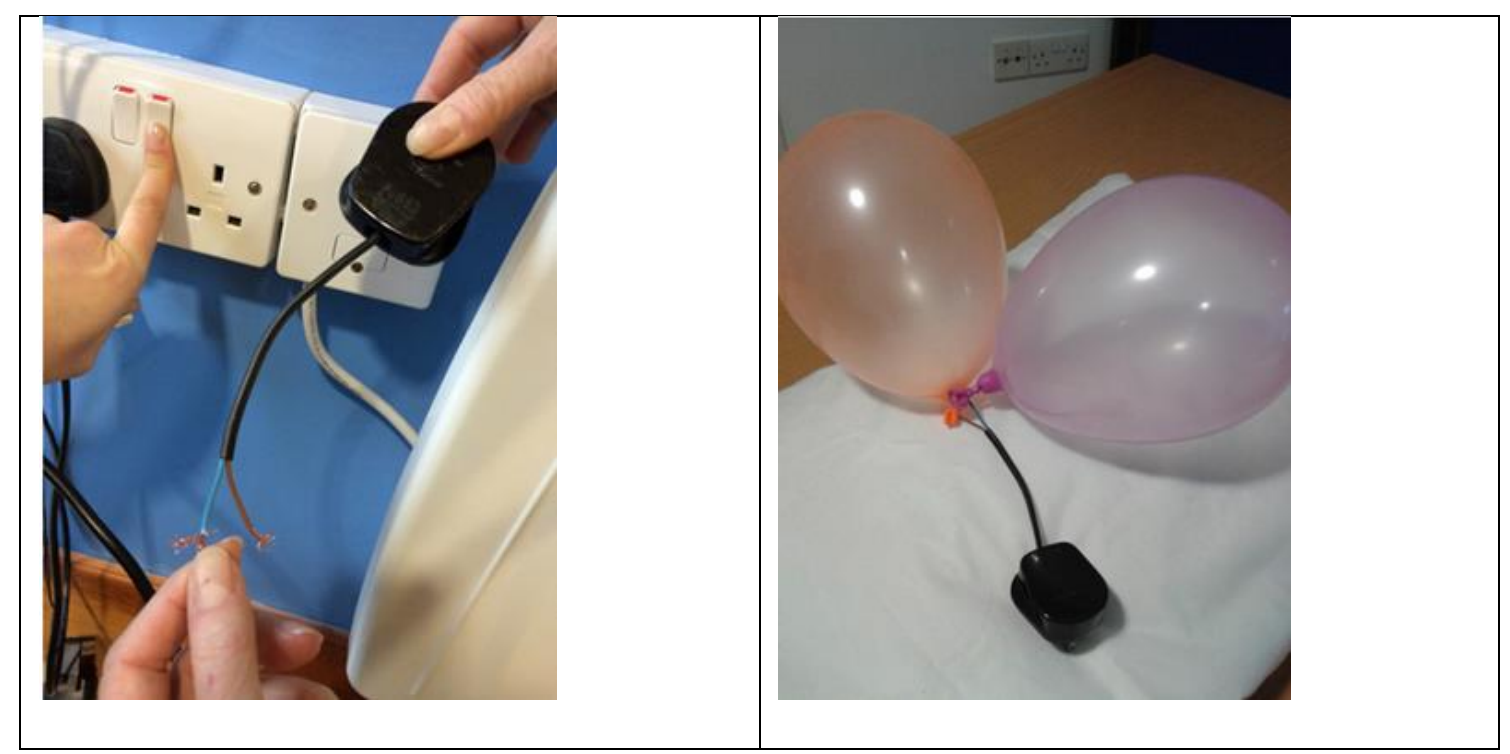

Figure 2: Digital photography workshop: Clara's 'before' and 'after' images (CC BYND-NC 4.0)

For the person whose trigeminal neuralgia felt like electrocution, adding balloons was not a 'realistic' transformation but one that employed humour:

Clara: humour is important - for me it was going towards hope. I just have to do that all the time. A desperate optimist that's what I am. It went from the bare wires, and plugging in and electrocuting myself to earthing. That was rubber that would stop the wires from being electrically charged. 
In one poignant exchange, a carer working with someone with pain (not the person she normally cared for) said, 'I want to take it [the ball of pain] from you', and the person with pain replied, 'but I don't want to give it to you.' From this interaction sprang a series of photos of the two of them struggling over ownership of the painful object before finally cradling it together, the carer's hands cupping the hands of the person with pain while she held the object.

Images enable 'open expression while maintaining concrete and explicit reference points' (Collier \& Collier 1986: 105), thus allowing novel dialogues to emerge. The objects made relationships to pain malleable in the sense that participants could reorient themselves to the object. The modifications represented shifts: of atmosphere, degrees of tension, containment or attitude, rather than major breakthroughs. Participants did not conjure up a state of being 'pain-free' but made more bearable versions of their pain.

A related process occurred collectively in the sound workshop. Some of the sounds which participants brought in were powerfully aversive: a recording of a baby's cry; a screeching violin string. In a group improvisation exercise, the sounds were 'treated' electronically and mixed together to create soundscapes that were inviting and bearable or even pleasant to listen to. The repetition of a line from a poem provided temporal coherence to the improvisation, countering the unpredictability of the sound of volcanic explosions. Surrounded by other sounds, the violin string was less awful. Sound thus functioned as a metaphor for pain's chronicity. Like persistent pain, sound could be made more listenable. The group improvisation put aversive sounds together, 
creating a system of support that changed their relations rather than desensitising. The work of listening to each other, responding, and recording a collective output produced a powerful collective feeling of accomplishment, solidarity and enjoyment, which was expressed in the evaluation forms (e.g. "A fantastic 'coming together' of sounds to produce the "messy reality of pain"”; "Uplifting experience for everyone who was unfamiliar with using sound to communicate").

\section{The Sociality of Pain}

The relationship of the person with pain to those without pain is a key feature of many studies on pain, particularly relations with clinicians (Kenny 2004; Ong \& Hooper 2006; Werner \& Malterud 2003) and carers and family members (MacNeela et al. 2013; Richardson et al. 2007). Making pain material through arts-based methods also enabled communication about the caring relationship, as suggested by the example above of two participants struggling over the pain object. The relationship of each person to the pain and to each other could be externalised in the objects, allowing discussions of themes that were otherwise difficult to verbalise.

\section{Caring Work}

In the first workshop, attended by an even number of clinicians and people with pain, there was significant bridging work and ongoing discussion of the importance of 'seeing clinicians as human beings' by both groups. Yet in other workshops the role of the clinician was less central, and participants did not invoke their experiences of clinical encounters in absentia. 
Richardson et al. (2007: 360) note that 'in the context of chronic widespread pain the term "supportive partnership" seems to better fit the nature of the caring' than the common identification of one partner caring for the other. In our workshops, participants frequently spoke of wanting to protect others from their pain and its chronicity. As one put it:

Lys: I sometimes think with chronic pain, you sometimes don't want to talk about it and bring it up because it gets quite boring for people who are not experiencing it around you ... it gets, um, boring for other people to hear it constantly because they don't feel it.

The workshop provided a space where she could speak to others with pain, and an awareness, as she reflected afterwards, that perhaps talking about pain was important, rather than simply something that bored others.

Sound was a particularly poignant prompt for discussions of care. Unlike photography, which evoked pain but did not generally trigger it, sound was sometimes literally painful. For the research team, this constituted an ethical problem. In the early part of the workshop, participants discussed and reproduced sounds that represented their pain, such as the screeching of windshield wipers, an explosion, two sheets of metal rubbing together, or a spoon being dragged against a metal grater. They also explored making noises with various sound objects placed in the room. The research team handed out earplugs and encouraged participants to step outside the room if they needed to, which some did. 
Participants were acutely conscious of the role of sound in triggering pain, and its impact on others. As one put it:

Luis: For me the entire experience just made me feel self conscious, you know, who is going to be annoyed? ...I guess it brought me to the notion that one has to be self conscious in terms of how we express of pain, how we make it sound, because there is a sense that my pain and the way I express that I don't want it to be uncomfortable for other people.

A physiotherapist noted:

Jane: If it's an image you can look the other way, but when the sound is going on around you, you can't get away from it. And in my experience of treating it and listening to stories all the time it's not possible to get away from that experience.

Working with sound collaboratively also provided insights into what participants felt might be helpful in the processes of listening, responding, judging where one could contribute and how much was 'too much'. As participants reflected afterwards:

Jane: I think what I really like about it is that you really have to listen to see where you fit in. And you can feel where the gap is. That's what's two-way about sound, you make the sound and listen back again Luis: yeah. Sometimes I would drift out. I remember I was playing my sound and then come back to what Katarina was doing. Gordon: And then sound loops can be quite hypnotic. 
Naomi: One of the things I found useful, because I had a few discomforting sounds, but listening to the way they interacted, and listening to the hypnotic thing and coming back to rhythm was quite hypnotic. Actually the violin which was quite painful was transformed in the overall. I was quite sceptical...

Luis: you have to give a sound to tune in to the sound Naomi: what I found comforting was the heartbeat, it was like a guarantee that life was going on anyway.

\section{Pain, Self and Space}

In the first workshop, discussion repeatedly returned to whether pain was experienced as inside or outside the body, and whether tuning in or blocking it out was more helpful. The images produced in mind mapping and body-scanning exercises showed pain conceptualised as outside, as something that drags down, swarms, drowns or encapsulates. Other metaphors such as toxic or tearing apart, or pictures of red saws and weapons, were unclear as to whether they were conceptualised as coming from outside, as damage, or from within, as something the body does to itself, or indeed both. The drowning person shouting 'help' and the person at the bottom of the well wondering 'where am I?' demonstrate the sense of isolation that often comes with pain; reaching out which is not met with reciprocation.

Clinicians at the first workshop said that questions of agency and ownership of pain came up repeatedly amongst their patients. For those with pain, these questions were 
a key part of their sense-making:

Ana: for me [pain] was coming all from the inside, so it was hard to get a sense of the outside, like everything was in it, coming from my core... but at the same time we were talking about this core, and it was like... because I made this drawing there (pointing), the core itself is not the pain. The pain is all around my core and [it's important to] keep this in mind.

In the second workshop, the bodywork practitioner leader suggested that there was a self to be recaptured outside pain, a 'you without pain'. Participants resisted the value judgement implied by this, that seeing one's self as bound up with pain was a bad thing, and separating one's self from pain was better.

Naomi: I find this notion of 'you is you' without the pain in a sense, it's very difficult if you've had it for over half your life, it becomes part of you because it has damaged you in all sorts of ways...I have learned from it things I don't think I would have learned without it. So the fact of a particular kind of fellow feeling or empathy, which I think is what we are complaining about or we find difficult when people don't have it, and we feel outside. That's not comfort but I wouldn't want to give it up either.

For Naomi, denial of pain suggested a denial of self. Silvia felt that denial also exacerbated the pain:

Silvia: I'm finding it difficult because to me there is the pain and then working against it, and the rejection just makes it worse, so then, the, embracing it, seems to feel to me that it's ok, it is part of me and it's alright. 
While this particular conversation had an uncomfortable (for the researchers) atmosphere of polarization between the co-leader who endorsed 'separating oneself from pain', and the participants who disagreed with him, this polarization was not insurmountable. Later in the workshop, Naomi accepted the practitioner's offer of bodywork and communicated that she was impressed with its effectiveness. And, when the issue of a self without pain emerged in the following workshop, two weeks later, she spoke quite differently:

Naomi: Although theoretically I disagree with this entirely, I found it incredibly helpful. I was thinking, 'there is a me outside all of this shit'. Very interesting contradictions between theoretically and physically. It is a kind of dissociation.

Participants described the workshops as having offered them opportunities to try out alternative ways of relating to their pain. As one participant put it 'I have not looked at pain in this way before. It has given me a new weapon in the arsenal' (Body Mapping evaluation). The workshops provided a safe space for engaging with alternative approaches. On an evaluation form, one participant reported valuing 'Having the time and space to stay with my pain creatively and supportively' (Body Mapping). Another appreciated 'Taking ourself out of the isolation of pain by confronting it collectively rather than by distraction and repression' (Sound).

\section{Conclusion: Arts Workshops as Pain Communication}


The arts workshops produced versions of pain as both extraordinary and a part of ordinary life. When transformations were produced, they were modest, foregrounding living with and managing pain, rather than becoming pain-free. When the location of pain was discussed, it focused on the pragmatic question of whether it was helpful to consider pain as a part of or separate from the self, not the aetiological question of origin. Discussion sidestepped mind/body dichotomies to ask more functional questions of how best to manage and live with pain. Overall, the workshops yielded nuanced, respectful versions of pain, in a field dominated by morally loaded binaries. The workshops as a research method, we argue, created a novel material and social context for the production of versions of pain.

Materially, the workshops supported participants to do and make things together. This process diffused individual pain narratives and built a sense of collective purpose. The use of objects and materials allowed for experimentation, play with evocative metaphors, malleability and change. Using arts materials to communicate about pain does not replace language, but augments it. Communication about pain is often investigated in a clinical context (Risdon et al. 2003). With this context come particular stakes: clinicians' stakes in diagnosis, treatment and referral; the stakes of people with pain in having their pain recognised and treated; eligibility for social security benefits. The ways that arts practices afford ambiguity and resist finalising interpretations, we suggest, contributed to an ethos of acceptance of the validity of participants' communications about pain, in their own terms, with no need for asserting the validity of one definition over another. 
Moreover, and as we have argued elsewhere (Tarr et al 2017), the process of making things in relation to pain was productive and produced a collective sense of achievement. This echoes the productive role of art in activist communities noted by Radley and Bell (2007), but also adds weight to Scarry's claims regarding the transformative potential of making: 'the human being who creates on behalf of the pain in her own body may remake herself to be one who creates on behalf of the pain originating in another's body' (1985: 324).

The participants' evaluations of our workshops also speak to the potential benefits for wellbeing of collective, directed activity. Some participants had avoided pain support groups, not wanting to be identified primarily on the basis of their pain. Yet they commented on how positive it was to meet others dealing with chronic pain, which is often an isolating experience. These workshops illustrate the positive, wellbeingenhancing value of working together without an explicitly therapeutic goal. Future research could explore whether and to what extent arts workshops could be used productively in other settings, including clinical ones.

Arts-based workshops are of course not a panacea. The workshops were resourceintensive to organise and both data and analysis were complex due to the multimodal nature of the material. This means that such workshops may be 'high risk' relative to well-established and relatively efficient interview methods. Moreover, as we have argued throughout, each method constitutes its object in particular ways. Arts workshops encourage creative, inclusive expressions. For pain communication research that explicitly seeks to improve clinician-patient, or patient-carer communication, localisation in a clinical setting is both relevant and appropriate. 
For medical sociology, arts workshops are a new tool for 'seeing health and illness worlds' (Harrison 2002). They also help to create new versions of these worlds. Mind/body dualisms which emphasise sensation over emotion, have been at the heart of medical and psychological versions of pain (Bendelow \& Williams 1995). Other versions of pain are also possible, and alternative research methods are capable of producing different versions. Our research demonstrates the value of arts-based methods for the sociology of health. The novel material and social environment of the workshops allowed for the 'performance' of alternative versions of pain. Given this, we suggest that participatory arts workshops are likely to be useful methods in contexts where verbal debates are well-established or stereotyped, and where social researchers seek to generate alternatives.

\footnotetext{
Notes

${ }^{1}$ Communicating Chronic Pain: Interdisciplinary Strategies for Non-Textual Data was supported by a grant from the Economic and Social Research Council via the National Centre for Research Methods, Grant number DU/ 512589108.

${ }^{2}$ Where words are quoted, pseudonyms have been assigned to all participants. We have resolved ethical challenges surrounding authorship and ownership of artistic outputs by crediting participants' real names on images unless pseudonyms were requested. We are aware that at times this severs the link between participants' narratives and their outputs, however, our aim was to consider collective rather than individual expressions of pain.
}

\section{References}

Attride-Stirling, J. (2001) Thematic Networks: an Analytic Tool for Qualitative 
Research, Qualitative Research 1,3, 385-405.

Back, L. and Puwar, N. (2013) Live Methods. Oxford: Wiley-Blackwell.

Bendelow, G. and Williams, S.J. (1995) Transcending the dualisms: Toward a sociology of pain. Sociology of Health \& Illness 17, 2, 139-65.

Bendelow, G. (2000) Pain and Gender. New York and Harlow: Prentice Hall.

Broom, A.F., Kirby, E.R., Adams, J. and Refshauge, K.M. (2015) On illegitimacy, suffering and recognition: A diary study of women living with chronic pain. Sociology 49, 4, 712-31.

Bourke, J. (2014) The Story of Pain: From Prayer to Painkillers. Oxford: Oxford University Press.

Braun, V. and Clarke, V. (2006) Using thematic analysis in psychology.

Qualitative Research in Psychology, 3, 2, 77-101.

Bury, M. (2001) Illness narratives: Fact or fiction? Sociology of Health \& Illness $23,3,263-85$.

Collier, J. and Collier, J. (1986) Visual Anthropology: Photography as a Research Method. Albuquerque, University of New Mexico Press. 
Clemente, I., 2009. Progressivity and participation: children's management of parental assistance in paediatric chronic pain encounters. Sociology of Health \& Illness, 31,6, 872-888.

Crawford, C.S. (2009) From pleasure to pain: The role of the MPQ in the language of phantom limb pain. Social Science \& Medicine 69, 655-61.

Fraser, K.D. and al Sayah, F. (2011) Arts-based methods in health research: A systematic review of the literature. Arts \& Health 3,2, 110-145.

Gleeson, K. (2011) Polytextual thematic analysis for visual data - pinning down the analytic. In P. Reavey (Ed.) Visual Methods in Psychology: Using and Interpreting Images in Qualitative Research. Hove: Psychology Press.

Harrison, B. (2002) Seeing health and illness worlds - Using visual methodologies in a sociology of health and illness: a methodological review. Sociology of Health \& Illness, 24,6, 856-72.

Heath, C. (1989). Pain talk: The expression of suffering in the medical consultation. Social Psychology Quarterly, 52,2, 113-125.

Heath, C. (2002) Demonstrative suffering: the gestural (re) embodiment of symptoms. Journal of Communication, 52,3, 597-616.

Henare, D., Hocking, C. and Smythe, L., (2003) Chronic pain: Gaining understanding 
through the use of art. The British Journal of Occupational Therapy, 66,11, 511-518.

Hydén, L.C. and Peolsson, M. (2002) Pain gestures: the orchestration of speech and body gestures. Health (London) 6,3, 325-345.

Jenkins, L. (2015) Negotiating pain: the joint construction of a child's bodily sensation. Sociology of Health \& Illness, 37,2, 298-311.

Jenkins, L. and Hepburn, A., 2015. Children's Sensations as Interactional Phenomena: A Conversation Analysis of Children's Expressions of Pain and Discomfort. Qualitative Research in Psychology, 12,4, 472-491.

Kugelmann, R. (1999) Complaining about chronic pain. Social Science \& Medicine $49,12,1663-76$

Law, J. and Urry, J. (2004) Enacting the Social. Economy \& Society 33,3, 390-410.

Lawton, J. (2003) Lay experiences of health and illness: past research and future agendas. Sociology of Health and Illness, 25,3, 23-40

Macneela, P., Doyle, C., O’Gorman, D., Ruane, N., McGuire, B.E. (2013)

Experiences of chronic low back pain: a meta-ethnography of qualitative research. Health Psychology Review 9,1, 63-82. 
Miczo, N. (2003) Beyond the "fetishism of words": Considerations on the use of the interview to gather chronic illness. Qualitative Health Research 13,4, 469-90.

Morris, D.B., 1991. The Culture of Pain. Berkeley: University of California Press.

Ong, B.N. and Hooper, H. (2006) Comparing clinical and lay accounts of the diagnosis and treatment of back pain. Sociology of Health \& Illness 28,2, 203-222.

Padfield, D. (2003) Perceptions Of Pain, Stockport: Dewi Lewis.

Padfield, D., Janmohamed, F., Zakrzwewska, J.M., Pither, C., Hurwitz, B. (2010) A slippery surface... can photographic images of pain improve communication in pain consultations? International Journal of Surgery, 8, 2, 144-50.

Padfield, D. (2011). 'Representing' the pain of others. Health (London) 15, 3, 241257.

Phillips, J., Ogden, J. and Copland, C., 2015. Using drawings of pain-related images to understand the experience of chronic pain: a qualitative study. British Journal of Occupational Therapy, 78,7,404-411.

Quintner, J.L., Cohen, M.L., Buchanan, D., Katz, J.D., Williamson, O.D. (2008) Pain medicine and its models: Helping or hindering? Pain Medicine 9, 7, 824-34. 
Radley, A. and Bell, S.E., 2007. Artworks, collective experience and claims for social justice: The case of women living with breast cancer. Sociology of Health \& Illness, $29,3,366-390$.

Radley, A. (2010) What people do with pictures, Visual Studies, 25,3, 268-79.

Rhodes, L.A., McPhillips-Tangum, C.A., Markham, C., Klenk, R. (1999) The power of the visible: the meaning of diagnostic tests in chronic back pain. Social Science \& Medicine 48,1189-1203.

Richardson, J. (2009) Editorial, Virtual Special Issue on the Sociology of Pain.

Sociology of Health and Illness

http://onlinelibrary.wiley.com/journal/10.1111/(ISSN)1467-

9566/homepage/virtual_special_issue_of_the_sociology_of_pain.htm last accessed 28 September 2016.

Richardson, J., Ong, B.N. and Sim, J. (2010) Experiencing chronic widespread pain in a family context: giving and receiving practical and emotional support. Sociology of Health \& Illness 29,3, 347-365.

Risdon, A., Eccleston, C., Crombez, G., McCracken, L. (2003) How can we learn to live with pain? A Q-methodological analysis of the diverse understandings of acceptance of chronic pain. Social Science \& Medicine 56, 375-386. 
Rowbotham, S., Holler, J., Lloyd, D. and Wearden, A., 2012. How do we communicate about pain? A systematic analysis of the semantic contribution of cospeech gestures in pain-focused conversations. Journal of Nonverbal Behavior, 36, 1, $1-21$.

Scarry, E. (1985) The Body in Pain: The Making and Unmaking of the World. Oxford: Oxford University Press.

Savage, M. (2013) The 'Social life of methods': A critical introduction. Theory, Culture \& Society 30,4, 3-21.

Smith, M.V. (2008) Pain experience and the imagined researcher. Sociology of Health \& Illness 30,7, 992-1006.

Stuckey, H. and Nobel, J. (2010) The connection between art, healing and public health: A review of current literature. American Journal of Public Health, 100,2, 254-63.

Tarr, J., Gonzalez-Polledo, E., and Cornish, F. (2017) On liveness: Using arts workshops as a research method. Qualitative Research, OnlineFirst: https://doi.org/10.1177/1468794117694219

Thacker, M. (2015) Guest editorial—-Is pain in the brain? Pain and Rehabilitation the Journal of Physiotherapy Pain Association. 39, 3-3(1). 
Toye, F., Seers, K., Allcock, N., Briggs, M., Carr, E., Andrews, J., Barker, K. (2013) Patients' experiences of chronic non-malignant musculoskeletal pain: A qualitative systematic review. British Journal of General Practice 63,617, e829-e841.

Vick, R.M. and Sexton-Radek, K., 2005. Art and migraine: Researching the relationship between artmaking and pain experience. Art Therapy, 22,4,193-204.

Werner, A. and Malterud, K. (2003) It is hard work behaving as a credible patient: encounters between women with chronic pain and their doctors. Social Science \& Medicine 57,8, 1409-19.

Williams, A., Davies, H.T.O., Chadury, Y. (2000) Simple pain rating scales hide complex idiosyncratic meanings. Pain 85, 457-63. 